A Journal for Language Learning Tydskrif vir Taalaanleer

\title{
UNCOVERING YOUNG CHILDREN'S EMERGING IDENTITIES RELATED TO THEIR LITERACY EXPERIENCES: SUGGESTIONS TO STRENGTHEN LANGUAGE EDUCATION
}

Melanie Moen, University of Pretoria.

Ina Joubert*, University of Pretoria

The study explored how young children's identities emerged from their drawings and accounts of their favourite stories as we argue the importance of understanding children in the context of school and language education. Sixty-six $(n=66)$ children of two urban schools in Pretoria, South Africa were asked to write about and draw their favourite story. The participants were between the ages of six and seven years. Vygotsky's socio-cultural theory and Chen's theory of the construction of identity in a social context were used as conceptual framework. This conceptual framework could be linked to the findings which suggested that the children related their drawings and versions of their favourite stories to their interpretations of their life worlds. The prominent themes from the data could be associated with the self, the family, familiar objects and known animals. Their literacy experiences and the socio-cultural influences on the children's construction of their identities were apparent in their work. We argue that teachers need to better understand how children understand themselves in relation to the world around them when making decisions about effective language education.

\section{Keywords}

Identity related to literacy experiences, young children, drawings, favourite stories, language education, understanding life worlds, socio-cultural context.

\section{INTRODUCTION}

Children spend many years at school. During this time they are educated and socialised to participate in the culture of the class, the school, the community and the country as a whole. However, not all children benefit from schooling as it impacts differently on children's learning and identity formation. Chen (2009: 1-3) stresses the confusion school systems have on children's unique sense of the self, for example in terms of sameness and differences. Schools set out to develop children's unique attributes, but are more often than not constrained by school policies and the need to have a uniform curriculum.

We argue that children's expressions of their emerging identities, especially related to their literacy experiences should be acknowledged in order to enhance language education and to strengthen teachers' commitment to each child's ability to become literate. Educational policies and programmes that exclude children's development of their sense of themselves becoming literate and their perspectives of their life worlds can limit their learning involvement and undermine their experiences of quality school life. In order to learn from children we need to be guided by the core conceptual mechanism of identity construction (Chen, 2009). The emergence of the self is one aspect of identity construction and relates to the discourse on multiple identities of young children which has been researched over the 
past decades (Duveen \& Lloyed, 1986; Phinney, Horenczyk, Liebkind \& Vedder, 2002. Developing an identity connected to their literacy experiences and their interpretation of their life worlds communicate the fact that language is culturally transmitted (Joubert, Bester, Meyer, Evans \& Phatudi, 2015).

Although the expression of the self is acknowledged as children's construction of their identification, it is rather difficult to ascertain. According to Hawkins (2002) one way of understanding the self is through drawing, but another way is through language and social context.

In this study we acknowledge that the concept of identity is multi-faceted, however, our main focus will be on understanding identity through the drawings and stories while being cognisant of the fact that development takes place within a particular social context and over time. From these perspectives we approached this study with the following questions in mind: What can children's drawings of their favourite stories tell us about their emerging identities? How can knowledge of children's drawings and stories assist teachers in enhancing language education?

\section{Identity construction}

Donald, Lazarus and Lolwana (2006), define identity as a sense of who you are and what your place in the world is. Contemporary theorists define identity as a complex and changeable construct, influenced by socio-cultural factors. Consistent with this view is the multi-dimensional model of identity formation and identity maintenance. Jones and McEwan (2000), suggest that identity is also negotiated in social contexts in an iterative process. Therefore, identities are affirmed and discredited by the individual as well as being validated and challenged by others. Although we are in agreement with the above statements we support the view that identity entails action as well as a situation in which children as social actors develop ways of solving problems in life (Chen, 2009).

Adults play a significant role in the formation of children's identities, particularly in offering ideas and ideals through communication that includes language (Joubert et al., 2015). However, children are also actively involved in their own identity construction. When considering identity, aspects such as age, gender and social status also contribute to a child's identity. Nesdale and Flesser (2002), discovered in their study of social identity that children as young as 5 years of age are sensitive to the status of their social group. As a child starts spending more time at school the range of experiences increases significantly and the desire for consistency motivates the child's gender conduct. Therefore the child falls back on gender as the means of sensing consistent identity, both experiencing consistency of self and consistency of others (Warin, 2000: 211).

From a socio-cultural framework, Edmiston (2010) argues that identities are formed in two complementary and intersecting ways. On the one hand, from a cultural viewpoint identities are determined by the narratives and practices that particular groups share and that people identify with when they regard themselves as group members. On the other hand, from a social constructivist viewpoint identities are formed as people consistently position themselves in the view of what others with more or less power, authority, and status think of them (Edmiston, 2010). According to Chen (2009), children construct their identity in a social context incorporating structure and agency in becoming a social being. 


\section{Identity and drawing}

In recent years there has been a shift from de-contextualising children's drawings towards an interest in children's meaning making through drawing and the socio-cultural contexts of the drawing activity (Hall, 2010). According to Hall (2010), children's identities can be called into being through the method of drawing. She is of the opinion that drawing is a cultural resource, a type of intellectual play, involving aesthetics, imagination, fantasy, reality and innovation. Drawing, when it combines everyday experiences with imagination offers an authoring space for the self (Hall, 2010: 97). Drawing is a spontaneous activity for a child, a sort of game, an escape and at the same time the discovery of total freedom that allows the expression of his desires as well as the deliverance from his fears. Therefore, drawing is an important diagnostic tool for therapists and educators alike (Hawkins, 2002). According to Hawkins (2002), the self is the source of all artistic activity in young children. He is of the opinion that the imaginary, the self and self-expression refer elliptically to each other. Therefore, the self is the source of self-expression or self-expression is evidence of self (Hawkins, 2002: 210).

Drawing has been undeniably recognised as one of the most important ways that children express themselves and has been repeatedly linked to the expression of personality and emotions. Children's drawings are thought to reflect their inner worlds, depicting various feelings of both conscious and unconscious meaning and relating information concerning psychological status and interpersonal style. Although children may use drawing to explore, to solve problems or simply to give visual form to ideas and observations, the overall consensus is that art expressions are uniquely personal statements (Malchiodi, 1998). Around the 1940's the study of drawings as representations of internal psychological conditions were explored. Drawing was thought to offer an alternative to self-expression that could bring out information that words alone could not (Malchiodi, 1998). Naumburg was one of the first people to use art therapy as a spontaneous method to explore children's life worlds (Malchiodi, 1998).

For children, art is a process that brings together many different experiences to create something new, personal and unique (Malchiodi, 1998: 1). The process of drawing requires the child to choose, translate, and arrange lines, shapes and colours to convey a thought, feeling and event. At the ages of four to seven, children draw what is relevant to them and leave out irrelevant information. Through their drawings one can determine what is unique to their life worlds. Therefore, children at this age draw what they know and understand (Wiechers, n.d.).

\section{Identity and language learning}

Vygotsky (2012) argued that the transmission and acquisition of cultural knowledge such as literacy takes place on an interpersonal level between individuals before it is internalised on an intrapersonal level within the individual self (Kendrick \& McKay, 2002). Miller, Mintz, Hoogstra, Fung and Pots (1992: 46) agree with Vygotsky as they state the importance of language learning which beyond the sentence level, is the means of self-understanding. They also believe that self-development is a product not only of cognitive change but of interpersonal experience mediated through language.

It is believed that there is a special affinity between narrative and the self, closely related to the way that people conceive themselves in terms of stories (Miller et al., 1992). Miller et al. (1992) believe that insofar as we account for our own actions and for major human events 
that occur around us in terms of narratives and stories, it is possible that our sensitivity to narratives provides the major link between our own sense of self and our sense of others in the social world. Norton (2012: 414) concurs with the above but expands these arguments as she believes in the significant relationship among identity, language learning and classroom teaching.

\section{Identity and socio-cultural theory}

This study adopted Vygotsky's socio-cultural theory and Chen's (2009) ideas about children's construction of identity in a social context in becoming a social being as basis for the conceptual framework (Vygotsky, 2012). Vygotsky viewed literacy as cultural knowledge and drawing as a way of knowing, as a particular kind of speech. He emphasised the critical role of drawing in young children's concept development, which includes self-concept and identity. Through drawing children engage in language use and this provides an opportunity for them to create stories (Vygotsky, 2012). In this study we regard the children's constructions of their identities through writing and drawing as socio-cultural indicators which need to be foundational to language education. We concur with Gunning (2013: 530) who states that the construction of a language programme starts with the children and who they are. The main focus of this study is to gain a better understanding of how these children understand themselves in relation to the world around them.

\section{METHODOLOGICAL CONSIDERATIONS}

In this case study we selected sixty-six children between the ages of six and seven from two urban schools in the Tshwane South district of Pretoria. These schools represent a sample of the diverse South African population. The first school in the study can be described as an inner-city school. The neighbourhood mainly consists of apartment buildings, where the majority of children live. The area is well known for its crime and unemployment, and there are many homeless children living on the streets. The school can be described as a multiracial school. The children speak different home languages, but the school's language of instruction is English. The second school is in a middle class neighbourhood within the city. Most of the children speak Afrikaans and the school's language of instruction is Afrikaans.

As children are vulnerable participants we respected the views of the children and employed the principles of informed consent and anonymity (Viviers, 2010). Written consent was obtained from the school and parents of the children who participated in the study.

A seven-year-old child falls within the middle childhood period of development. During this period in school and wherever they spend time, children acquire the fundamental skills considered to be important by their culture such as reading, writing and arithmetic. Skills of self-awareness also develop dramatically in middle childhood. According to Eccles (1999) the age period between seven and eleven is described as industry versus inferiority. Children busily learn to be competent and productive, or feel inferior and unable to do anything well (Eccles, 1999). During this period Chen (2009: 3) reports that children regard drawing and writing to be a high motivator for taking part in learning activities and this informed our methodology for the project.

The study was conducted at the end of the children's first year of formal education. The children were used to the class and school system. They were also taught to use writing skills to give their versions of their favourite stories. 
The primary focus of the study was to explore the children's literacy narratives within their socio-cultural context to inform language education. The children were asked to draw and write about their favourite story in order to determine what they regard as their favourite stories, as stories are important for any language programme in the early years. However, after examining the children's contributions it was clear that they conveyed important information relating to their identities (Alerby, 2000). This visible emergence of their sense of self, motivated us to write the article, as identity-related issues are becoming increasingly important in current research (Joubert, Ebersöhn \& Eloff, 2010).

Qualitative content analysis was used, which can be described as a more linear and structured approach often used in narrative approach dealing with identity (Murray, 2009). With the analysis of the data we aimed to explore the meaning of the thoughts moulded by the children. During the analysis stage the textual data were viewed as a whole. In line with the analytical procedures, all the data were analysed. This procedure was done in a repeated and thorough manner, viewing each drawing and narrative as a unit and noticing qualitative similarities and differences, patterns and structures. These patterns and structures were then combined in different themes, taking the common and central characteristics of the patterns as the point of departure.

\section{FINDINGS}

Even though the children were encouraged to draw and write about their favourite stories their construction of their identities was mostly shaped by their experiences of literacy, interpretations of their life worlds, socio-cultural worlds and familiar objects in their life worlds. Those participants who wrote about fantasy stories chose predominantly the story of the three little pigs, which relates closely to the family and the home. In the next section the findings are discussed in relation to the self, family and familiar objects, stories and identity as well as socio-cultural influences and identity. The findings will be discussed as school 1 and school 2. The different classes in school 2 will be indicated as class 1 and 2. The participants are numbered from 1 to 66 . The original quotations (without corrections) as they were written by the participants will be used throughout this section.

\section{Identity in relation to the self, family and familiar objects}

The participants' responses related closely to the self, family and familiar objects in their life worlds. The participants often included themselves in their drawings, as well as their families and familiar objects. In the responses the participants included objects, such as a toy and sometimes even gave human-like attributes to animal characters in the stories.

Participant 1 (school 2 class 2) did not write or draw her favourite story, but she chose her house, sisters and cat. She even included a still life scene of a sun, tree and flowers in her drawing. Her narrative also related to herself, her sister and the cat.

'I am a woman. My name is ... I am a girl. I have a pet is a cat.' 


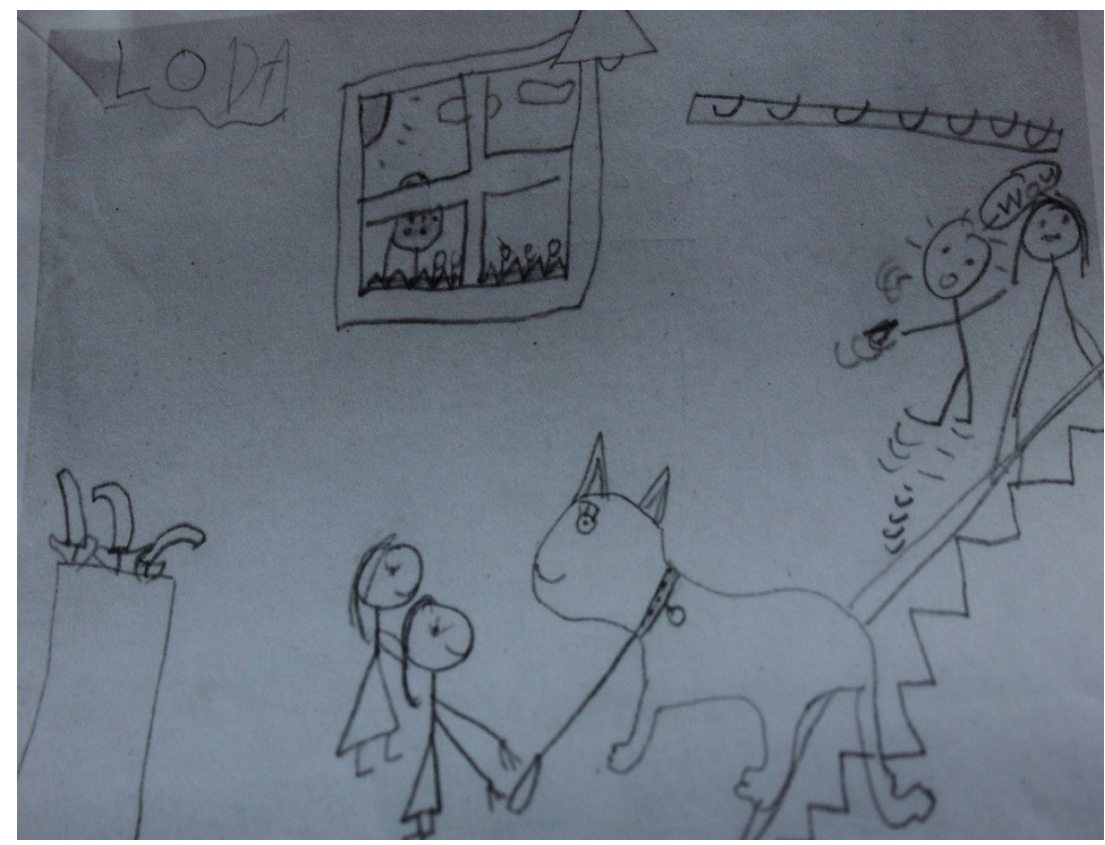

\section{Drawing 1. Participant 1 (school 2 class 2)}

Participant 2 (school 2 class 2), wrote about her house, her dog and a familiar animal in the South African context, namely the crocodile.

'I am scade of a croc. I am not scade of a dog. I do not like to see croc in the house.'

Participant 4 (school 1) wrote about Arrie apple, a story he read during his first year of school. His drawing was of familiar objects such as a horse, dog, cat, trees, apple and a house in a tree. Even though his narrative was about a familiar story, his drawing included a house which was not mentioned in the original story.

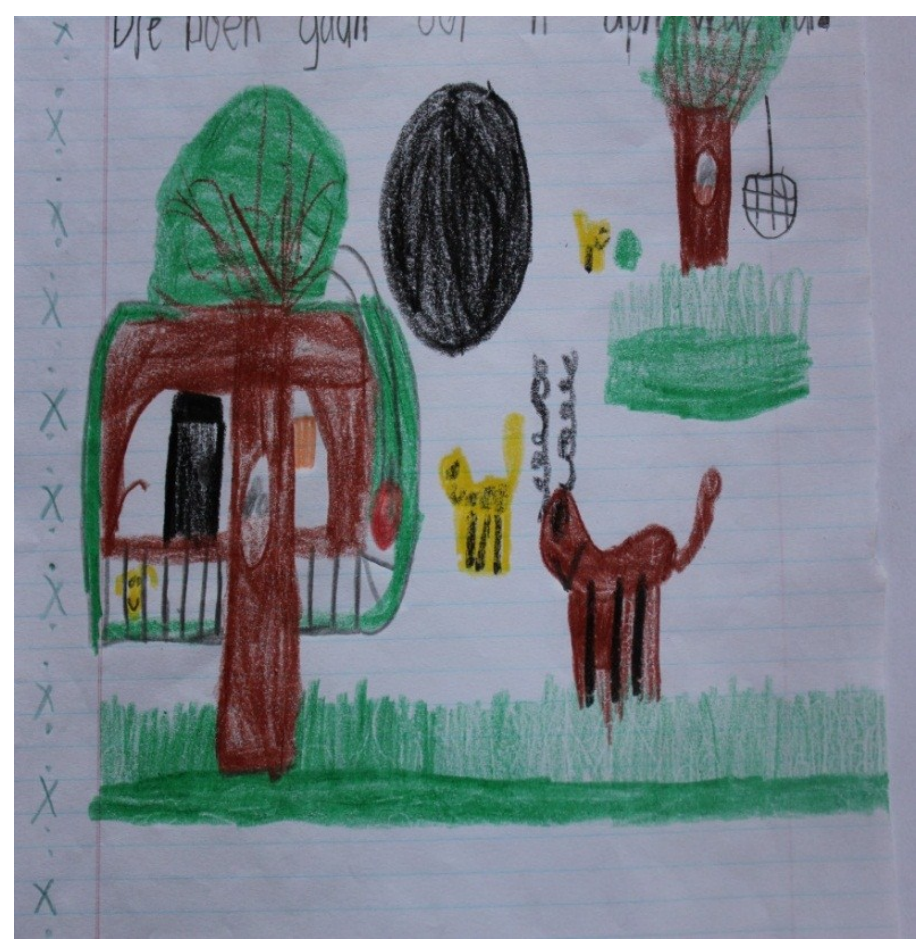




\section{Drawing 2. Participant 4 (school 1)}

Participant 11 (school 2 class 1) did not write about a story but chose to write about her pet snake, herself and the sun. She described herself as good and drew a detailed self-portrait.

'I love my snyak. I am good. Look at me. I see a sun.'

Participant 9 (school 2 class 1) wrote about himself, the dog and his mother. He chose to relate his narrative and drawing to the self and home environment.

'I am a boy. Look at the dog....My mommy is good.'

\section{Stories and identity}

A significant number of children chose the familiar story The Three Little Pigs to write and draw about. The story is a popular and well-known story in many countries and cultures and South Africa is no exception. The story is about a family of pigs, their home environment, the threat of a wolf and how this challenge was resolved.

Participant 3 (school 2 class 1) wrote and drew the story of The Three Little Pigs. She drew one pig with human features and a house.

'I have a plan that's makes house yes that's a good plan'

Participant 4 (school 2 class 2) also drew the three little pigs, but in her drawing she added a fire and toy car. In her narrative she included a sister, which is different from the original story.

'The wolf saw the pigs. The sister said I will make my house here.'

Participant 6 (school 2 class 2) wrote the following about the three little pigs:

'I am not afaid of the wolf and the wolf is in the house.'

Participant 15 (school 2 class 1) wrote the following:

'The three Littl pigs. We are happy.' 


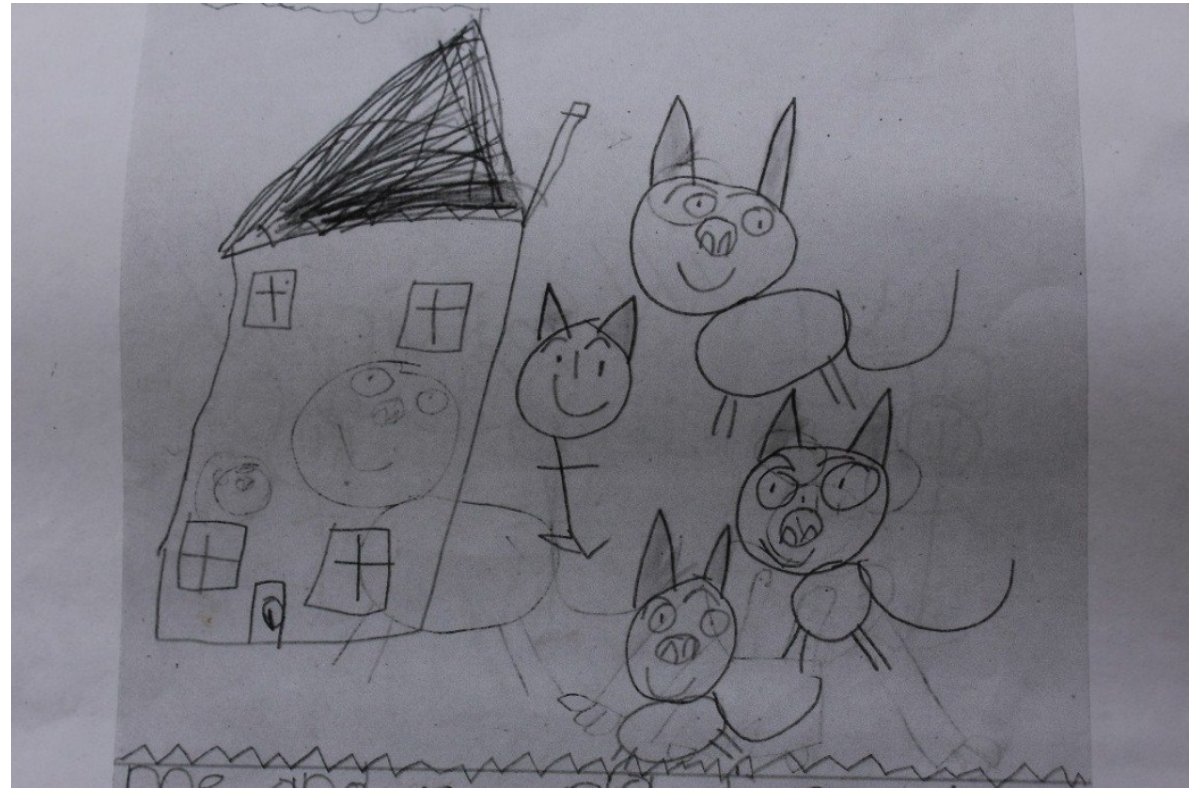

\section{Drawing 3. Participant 15 (school 2 class 1$)$}

Participant 10 (school 1 class 1) chose the story of Goldilocks. She drew a house with three chimneys and a girl outside the house.

'My beste storie is gouelokkies want ek hou baie van bere.' The sentence was translated by the researcher as [My favourite story is Goldilocks, because I really like bears]

\section{Socio-cultural influences and identity}

The children in this study related their responses to familiar objects and the socio-cultural influences emerged in their work. Some stories included familiar scenes of the home environment. Quite a few of the responses included interactions at home and with friends and others were related to the school environment. A significant number of children included animals in their responses. The animals were mostly familiar animals within the South African context such as snakes, lions, spiders, monkeys and crocodiles. The animals that were chosen are well known in the African context and children often have close knowledge of these animals. Domestic animals such as cats and dogs were popular in the children's responses. The children also included well-known environmental objects in South Africa such as the sun, clouds and trees in their drawings. There were pictures of outdoor fires and families sitting next to the fire. There were also drawings of children interacting with family members and domestic pets in the home environment.

Participant 7 (school 2 class 2) wrote and drew a house, a man, a boy, cat, spider, fire and star.

'...he makes my cat angry very very angry...'

Participant 9 (school 2 class 1) drew the story of The Three Little Pigs, but mostly wrote about the pigs enjoying jumping and playing with the ball. He also mentioned playing at his dad's house.

'...las go play the ball...' 
Participant 13 (school 2 class 2) related his work to a snake and his yo-yo toy. He also drew himself, clouds and the sun.

\section{'With my yo-yo I can bit the snake...'}

Participant 17 (school 2 class 1) wrote the following:

'My mom is nice. We go to school.'

Participant 11 (school 1 class 1) wrote the following:

'Die kinders was rof toe hulle by die see kom.' The sentence was translated by the researcher as [The children were rough when they arrived at the seaside]

Participant 12 (school 1 class 1) wrote a story about a horse. She drew the horse and clouds.

'Die perdjie kalop na sy huis.' The sentence was translated by the researcher as [The horse galloped to his house].

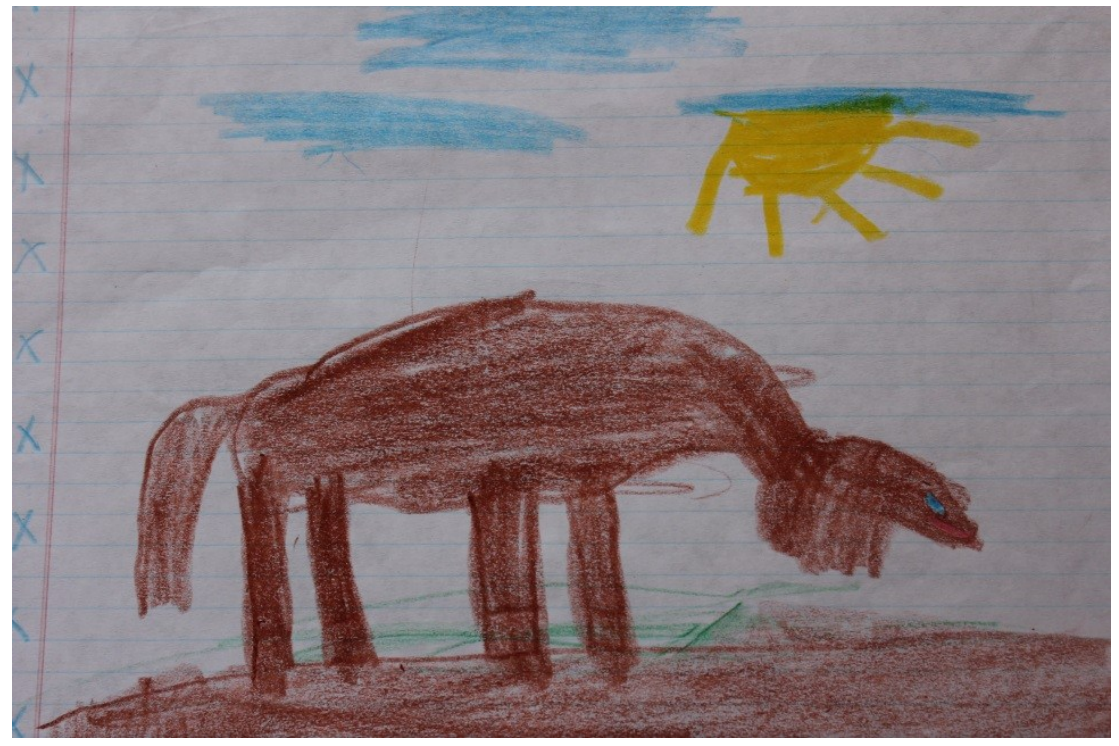

\section{Drawing 4. Participant 12 (school 1 class 1$)$}

\section{DISCUSSION}

The children in this study were asked to draw and write about their favourite stories as we considered this data collection activity a purposeful task for these young children. Through this task we hoped to determine how knowledge regarding children's graphic representation of their stories as well as their short narratives thereof can assist teachers in enhancing language education. We maintain the importance of understanding children in the context of school and language education. We also argued that children's expressions of their identities, especially related to their literacy experiences should be acknowledged in order to enhance language education and to strengthen teachers' commitment to each child's ability to become literate.

It was evident through the qualitative analysis that their drawings and stories were mainly shaped by the self, their families, home environment and familiar objects and animals. 
Although we used data from two different schools to deepen our understanding, similar themes emerged from all the data. It seemed to us that the different socio-cultural worlds of the schools were not significant in the formation of the self and identity of the participants, as was expected in the beginning of the study. It was apparent through this study that drawing is an authoring space for the self and that children draw what they know and understand (Hall, 2010).

Drawing is seen as a cultural resource by Hall (2010). The majority of South African children can draw basic objects and figures when they enter school. Our participants had at the time of the study eleven months of formal schooling. Therefore, this was an easy, non-threatening task for the children. Through their drawings the children shared their inner worlds with us. We could get an idea of their feelings and thoughts through their drawings. Through their responses we could also explore and interpret the mix of fantasy and reality described by Hall (2010: 96). As mentioned before, most of the children chose to draw their life worlds which included familiar objects such as a house, dog, sun and people. We agree with researchers such as Hawkins (2002) who acknowledges the self as the source of all artistic activity in young children. The children in this study gave us a glimpse of their emerging identities through their drawings and through their understanding of themselves in relation to the world they live in.

Another important skill learnt during the first year of school is writing. Although the children in our study presented limited written language skills, they could still express their thoughts and feelings clearly through their stories. Their drawings also enhanced their narratives giving the researchers a more accurate view of the participants' perspectives. As the children presented limited language skills, the shorter sentences enabled the researchers to focus more clearly on the important words and themes in the lives of these children. Therefore, one can argue by writing shorter, basic sentences the children gave us the most important aspects of their life worlds. This however, can also limit the understanding in some cases. The participants in school 2were mostly second language speakers as English is not these children's home language. This study did not set out to investigate the children's language skills and further research in this field is suggested. The researchers concluded that by using the dual medium of writing and drawing they could explore the rich life worlds of the participants. The mediums of drawing and writing supported and also clarified the responses of the children.

According to Donald et al. (2006), identity is negotiated in social contexts. Identity is therefore negotiated, affirmed and discredited by the individual as well as people in the individual's life. The participants in this study related their responses to themselves, to their families as well as familiar institutions and objects in their lives. The participants often included themselves in their drawings, but also their families and things that they are familiar with. Even in the well-known stories like for instance The Three Little Pigs, the children included familiar people and objects like fathers, sisters and toys. In many cases they included animals. In addition, the children often wrote and drew about interactions with family, pets and friends. Vygotsky (2012) viewed literacy as cultural knowledge and drawing as a way of knowing. The children gave us an indication of their way of knowing and their cultural knowledge through their drawings and writing.

The story of The Three Little Pigs was chosen by a substantial number of children as their favourite story. The teachers of both schools confirmed that they have told this story to their learners. We argue that although the children have heard the story perhaps many times in 
their lives, they have chosen it as a favourite as it resonates with the family and home. According to Hughs (n.d.), fairy tales are an important tool for children learning to navigate reality and survive in a world ruled by adults. Hughs (n.d.), states that fairy tales can give insight into children's life worlds as they represent their actions in the social world (Bettelheim, n.d.). The participants in this study often humanised the drawings by drawing the pigs with clothes, arms, legs and feet. Their narratives sometimes included themselves, family members and even games they play at home and at school. One can therefore argue that the participants shared their unconscious and conscious worlds with us through their responses. By stating that their stories related closely to their life worlds, which again relate to their particular identities, the argument is strengthened.

According to Donald et al. (2006) one's identity is directly linked to one's socio-cultural world. In our study this was true for most of our young participants. Through a socio-cultural lens we could determine how they understood themselves in relation to the world around them. The children's responses related to the world they were familiar with and they dedicated their stories to themselves and their particular home environment. More than half of the children in the study drew or wrote about a house as part of their responses. In psychological terms the house in children's drawings can be interpreted as a place of safety, caring, nurturing and family (Buck, 1981). This gave us a glimpse of their identities within this particular socio-cultural context.

By drawing and writing the children gave a unique personal statement of their identities, of who they are in relation to their language experiences, their environment and where they belong in this world. In our study we found numerous examples of drawings which seem best understood as particular interactive engagements by children who are structuring and inventing drawing in relation to a number of contexts which can also be related to identity. According to Hawkins (2002: 210), the individual self takes meaning only within language and the social context within which language operates. In other words, the idea of the self as the source of expression is mistaken as the individual is constructed within the culture. We, however, argue that identity is shaped both by the individual, as well as by the particular socio-cultural context they find themselves in. This statement aligns with Chen's (2009) theory of children constructing their identity in a social context in becoming a social being and Vygotsky's (2012) description of language learning as a cultural experience.

We further posit that these young participants have something to say about themselves through their constructed identities without us claiming complete understanding of their identities. Teachers and stakeholders alike should take cognisance of young children's construction of the self, informed by their interpretations of their life worlds and their literacy experiences. When deciding on the school's policies and curriculum content, teachers need to include written activities that focus on the children's home lives and themselves. Children should also be given the opportunity to write about themselves.

\section{CONCLUSION}

The initial focus of this study was to look at children's literacy narratives, but through thorough analysis the researchers realised the importance of identity construction in the children's stories and life worlds. This analysis gave the researchers a rich look at these particular seven-year-old, urban South African children. 
Through their drawings and narratives the researchers gained valuable insights relating to these children's literacy experiences as well as their understanding of their life worlds as expressed through their constructed identities. The children related their work to themselves, their families and their life worlds. The significant themes and objects gave us a unique insight into the worlds of these young children. We gained an understanding of how important the home, family and the self are at this age. We also realised how valuable the socio-cultural worlds of these children are. By analysing their work we also discovered that children relate their world to familiar objects and people.

The data provided by the children open new possibilities for research into art, stories and identity in the early years of education. It leads us to understand how children construct their identities and gives us the opportunity to enquire about how we might strive to enrich our knowledge about identity in future. These insights can also assist teachers in adapting their teaching styles and the content of the language programme to develop their children's unique attributes and each child's ability to become literate in the classroom environment. It is important to remember the words of Hawkins (2002: 219) 'We are all artists who must draw, write, act, dance, speak and compose the eccentric propositions of our fate.'

\section{REFERENCES}

ALERBY, E. 2000. A way of Visualising Children's and Young People's thoughts about the Environment: A study of drawings. Environmental Education Research, 6(3):205222. Doi:10.1080/13504620050076713.

BETTELHEIM, B. n.d. Uses of Enchantment. Available from http://www.whiningkentpigs.com/DW/oldzones/perelandra35.pdf. [Accessed: 31 March 2014].

BUCK, J. 1981. The House-tree-person technique: A revised manual. Los Angeles: BrunnerRoutledge.

CHEN, R. 2009. Early childhood identity. Construction, culture, \& the self. New York: Peter Lang.

DONALD, D, S LAZARUS \& P LOLWANA. 2006. Educational Psychology in social context $3^{\text {rd }}$ Edition. Cape Town: Oxford University Press.

DUVEEN, G \& B LLOYED. 1986. The significance of social identities. British Journal of Social Psychology, 25(3)1:219-230.

ECCLES, JS. 1999. The development of children ages 6-14. The Future Children, 9(2) Fall 1999: 30-44.

EDMISTON, B. 2010. Playing with children, Answering our lives: A Bakhtinian Approach to Co-authoring Ethical Identities in Early Childhood. British Journal of Educational Studies, 58(2):197-211.

GUNNING, TG. 2013. Creating Literacy Instruction for All Students. 8th Edition. Boston: Pearson.

HALL, E. 2010. Identity and young children's drawings: power, agency, control and transformation. In Broadhead, P, J Howard \& E Wood. Play and Learning in the Early years: From research to practice. London: Sage. 95-113.

HAWKINS, B. 2002. Children's drawings, Self Expression, Identity and the imagination. International Journal of Art and Design Education, 21(3):209-219.

HUGHS, C. n.d. Psychology and fairy tales. Available from http://www.mccarter.org/education/secret wings/p16.htm. [Accessed: 1 April 2014]. 
JONES, RC \& MK McEWAN. 2000. A conceptual model of multiple dimensions of identity. Journal of College Student Development. Vol 41 (4): 405-414.

JOUBERT, I, L EBERSöHN \& I ELOFF. 2010. How post-apartheid children express their identity as citizens. Childhood, 17(3):396-410.

JOUBERT, I, M BESTER, E MEYER, R EVANS \& N PHATUDI. 2015. Literacy in the Foundation Phase. $2^{\text {nd }}$ ed. Pretoria: Van Schaik.

KENDRICK, M \& R McKAY. 2002. Uncovering Literacy Narratives through Children's Drawings. Canadian Journal of Education, Vol. 27(1):45-60.

MALCHIODI, CA. 1998. Understanding Children's Drawings. New York: The Guilford Press.

MILLER, PJ, J MINTZ, L HOOGSTRA, H FUNG \& R POTS. 1992. The narrated self: young children's construction of self in relation to others in conversational stories of personal experience. Merrill-Palmer Quarterly, 38(1):45-67.

MURRAY, G. 2009. Narrative inquiry. In J Heigham \& RA Croker (Eds), Qualitative Research in Applied Linguistics. Basingstoke: Palgrave MacMillan. 45-65.

NESDALE, D \& D FLESSER. 2002. Social identity and the development of children's group attitudes. Child Development, 72 (2): 506-517.

NORTON, B. 2012. Language, identity and the ownership of English. TESOL Quarterly, 31 (93): 409-429.

PHINNEY, JS, G HORENCZYK, K LIEBKIND \& P VEDDER. 2002. Ethnic Identity, Immigration, and Well-Being: An Interactional Perspective. Journal of Social Sciences. 57(3):493-510.

VIVIERS, A. 2010. A framework for the ethical principles of children's participation. MEd. Master in Social Work Dissertation. University of Pretoria.

VYGOTSKY, L. 2012. Thought and Language. Cambridge: MIT Press.

WARIN, J. 2000. The attainment of self-consistency through gender in young children. Sex roles, 42 (3/4): 209-231.

WIECHERS, P. n.d. Kleutertekeninge: Unpublished research. Pretoria: University of Pretoria.

\section{Biographical notes}

Melanie Moen is a researcher and lecturer in the Department of Early Childhood Education in the Faculty of Education at the University of Pretoria. She is a registered psychologist with an interest in youth violence. She is currently a PhD student in Educational Psychology.

Email address: melanie.moen@up.ac.za

Ina Joubert is an associate professor in the Department of Early Childhood Education in the Faculty of Education at the University of Pretoria where she acts as Head of Department. She is a member of the World Education Research Association and specializes in Democratic Citizenship Education and Language Education related to the young child.

Email address: ina.joubert@up.ac.za 